\title{
Women's Awareness of Mammographic Screening for Breast Cancer in Togo
}

\section{Abdoulatif Amadou ${ }^{*}$, Solim Nabede1, Pihou Gbande², Massaga Dagbe ${ }^{3}$, Lantam Sonhaye1, Lama Kedigoma Agoda-Koussema ${ }^{4}$, Komlanvi Adjenou1}

${ }^{1}$ Radiology and Medical Imaging Department, Centre Hospitalier Régional Kara, Kara, Togo

${ }^{2}$ Radiology and Medical Imaging Department, Centre Hospitalier Régional de Sokodé, Sokodé, Togo

${ }^{3}$ Radiology and Medical Imaging Department, Centre Hospitalier Universitaire de Kara, Kara, Togo

${ }^{4}$ Radiology and Medical Imaging Department, Centre Hospitalier Universitaire Sylvanus Olympio, Lomé, Togo

Email: *amadoulatif@yahoo.fr

How to cite this paper: Amadou, A., Nabede, S., Gbande, P., Dagbe, M., Sonhaye, L., Agoda-Koussema, L.K. and Adjenou, K. (2021) Women's Awareness of Mammographic Screening for Breast Cancer in Togo. Journal of Cancer Therapy, 12, 655-662. https://doi.org/10.4236/jct.2021.1212057

Received: October 8, 2021

Accepted: December 4, 2021

Published: December 7, 2021

Copyright (c) 2021 by author(s) and Scientific Research Publishing Inc. This work is licensed under the Creative Commons Attribution International License (CC BY 4.0)

http://creativecommons.org/licenses/by/4.0/

\begin{abstract}
Breast cancer represents a real public health problem due to its increasing frequency, its seriousness and its psycho-social implications. The aims of this study were to determine the level of awareness of women on the performance of mammography in the diagnosis and screening for breast cancer. This was a cross-sectional study over a period of 4 months (from October 1, 2016 to January 31,2017$)$ in Togo. It consisted in completing a questionnaire distributed to women above 30 years of age. The mean age of the women was 42 years. $88.8 \%$ of them had heard of breast cancer. There was a link between age, occupation, level of education and awareness of breast cancer. Only $20.8 \%$ of women had heard of mammography, with a link between awareness of mammography and age, occupation, and level of education. A link was noted between awareness of breast cancer and awareness of mammography. Information on mammographic breast cancer screening is inadequate in Togo.
\end{abstract}

\section{Keywords}

Breast Cancer, Women, Screening, Mammography, Information

\section{Introduction}

Breast cancer represents a real public health problem due to its increasing frequency, its seriousness and its psycho-social implications. It is the first cancer in women worldwide [1]. It is estimated that there were 14.1 million new cases and 8.2 million deaths from breast cancer in 2012 [2]. 
In sub-Saharan Africa, breast cancer is the second most common cancer after cervical cancer in women [3]. It seems to be more common during the period of genital activity between 35 and 45 years, i.e. 10 years earlier than in developed countries [3]. In Togo, the incidence of breast cancer is particularly high (17.09\%) [4]. It accounts for $15.8 \%$ of cancers in older women and ranks second among cancers in women after cervical cancer (16.2\%) [5].

Faced with this public health issue and in order to lower the mortality rate, developed countries have set up an organized screening program, making it possible to make the diagnosis as soon as possible. Indeed, breast cancer can be cured in $90 \%$ of cases when it is detected at an early stage [6]. The screening is done by clinical examination, and especially by mammography. In Togo a study by Agoda-Koussema et al. [7] in 2010 reported a sensitivity of $71.74 \%$ and a specificity of $89.65 \%$ in the diagnosis of breast lesions. However, in developing countries, no organized mammographic screening program has been established. Thus, each woman must manage to get an individual screening provided she is informed.

In addition, few studies have so far established the level of awareness of women on mammographic screening for breast cancer in Togo. The aim of this work was therefore to determine the level of awareness of women regarding mammographic screening for breast cancer in Togo.

\section{Materials and Methods}

\subsection{Study Procedures and Ethical Considerations}

Our study was carried out at the Centre Hospitalier Universitaire Campus in Lomé. This was a descriptive cross-sectional study over a period of 4 months (from October 1, 2016 to January 31, 2017). It focused on women of age to undergo mammography, over 30 years of age, not suffering from any breast pathology and having freely consented to answer our duly designed questionnaire which was administered to them.

The women who responded to the questionnaires were recruited in hospital, when they came for a medical consultation. Those who had once performed mammography were excluded from our study.

The women were submitted to a questionnaire that aimed to assess awareness about breast cancer and mammography screening, and to collect some sociodemographic data.

Anonymity was ensured by codifying the questionnaires.

\subsection{Data Collection}

Togo has a population of 8.6 million with $50.7 \%$ women. The sample size was defined as defined as 1 per 10,000 of the female population of Togo, with a margin of error of $10 \%$.

The files were entered into a database designed using Epi Info 7 computer software, with attention to confidentiality and anonymity. 
Tables and graphs were produced using Microsoft Office Excel 2019 and data entry was done using Microsoft Word 2019 software.

\subsection{Ethical and Deontological Considerations}

To preserve the anonymity of patients, a serial number was assigned to each data collection sheet, thus ensuring the confidentiality of the information collected.

\section{Results}

\subsection{Sociodemographic Data}

This study had registered 510 women, corresponding to an average of 127.5 women surveyed per month. The mean age of the women was 42.96 years (a range of 30 to 79 years). The most represented age group was the 30 to 49 years group with $82.4 \%$ (215 women) (Table 1 ). The most commonly found occupation was traders followed by craft workers, representing $44.1 \%$ ( 225 women) and $21 \%$ (10 women) respectively (Table 2 ). Uneducated women represented $24.1 \%$ (123 women) (Table 3$)$.

Table 1. Distribution of women according to their knowledge of mammography and according to age.

\begin{tabular}{ccccccc}
\hline & $\mathbf{3 0 - 3 9}$ & $\mathbf{4 0 - 4 9}$ & $\mathbf{5 0 - 5 9}$ & $\mathbf{6 0 - 6 9}$ & $\mathbf{7 0 - 7 9}$ & TOTAL \\
\hline Yes & 39 & 28 & 33 & 2 & 4 & 106 \\
No & 176 & 177 & 32 & 16 & 3 & 404 \\
TOTAL & 215 & 205 & 65 & 18 & 7 & 510 \\
\hline
\end{tabular}

$\mathrm{X}^{2}=33.7 ; \mathrm{P}<0.05$.

Table 2. Distribution of women according to their knowledge of mammography and according to profession.

\begin{tabular}{cccccc}
\hline & Craft worker & Trader/Retailer & Civil Servant & Housewife & TOTAL \\
\hline Yes & 10 & 21 & 54 & 21 & 106 \\
No & 97 & 204 & 28 & 75 & 404 \\
TOTAL & 107 & 225 & 82 & 96 & 510 \\
\hline
\end{tabular}

$\mathrm{X}^{2}=34 ; \mathrm{P}<0.05$.

Table 3. Distribution of women according to their knowledge of mammography and according to level of education.

\begin{tabular}{ccccccc}
\hline & None & Primary & $\begin{array}{c}\text { Lower } \\
\text { Secondary }\end{array}$ & $\begin{array}{c}\text { Upper } \\
\text { Secondary }\end{array}$ & University & TOTAL \\
\hline Yes & 8 & 8 & 29 & 21 & 40 & 106 \\
No & 115 & 50 & 142 & 74 & 23 & 404 \\
TOTAL & 123 & 58 & 171 & 95 & 63 & 510 \\
\hline
\end{tabular}

$\mathrm{X}^{2}=44 ; \mathrm{P}<0.05$. 


\subsection{Awareness of Breast Cancer and Mammography}

Women with awareness of breast cancer represented 88.8\% (453 women), and those with awareness of mammography were $20.8 \%$ (106 women).

Women under the age of 50 represented $63.2 \%$ (67 women) of women aware of mammography, and among women under 50 years of age, $15.9 \%$ were aware of mammography with a significant difference (Table 1).

Civil servants represented 50.9\% (54 women) of women with awareness of mammography, and among civil servants $65.8 \%$ were aware of mammography with a significant difference (Table 2).

Uneducated women $(7.5 \%$ or 08 women) and primary school level women ( $7.5 \%$ or 08 women) the least informed about mammography with a significant difference (Table 3).

Women with no information about breast cancer had never heard of mammography. Of those who had heard of breast cancer, only 23.4\% (106 women) had information about mammography with a significant difference (Table 4).

\subsection{Information on Mammography Screening}

Regarding information on mammography screening for breast cancer, 83 \% (523 women) of women found it unsatisfactory. Midwives and the media were the main sources of information for women, with $37.2 \%$ (190 women) and $36.1 \%$ (184 women) respectively (Figure 1).

Table 4. Distribution of women according to their knowledge of breast cancer and mammography.

\begin{tabular}{cccc}
\hline \multirow{2}{*}{ Cancer } & \multicolumn{2}{c}{ Mammography } & Total \\
\cline { 2 - 3 } & Yes & No & \\
\hline Yes & 106 & 347 & 453 \\
No & 0 & 57 & 57 \\
Total & 106 & 404 & 510 \\
\hline
\end{tabular}

$\mathrm{X}^{2}=16.83 ; \mathrm{P}<0.05$.

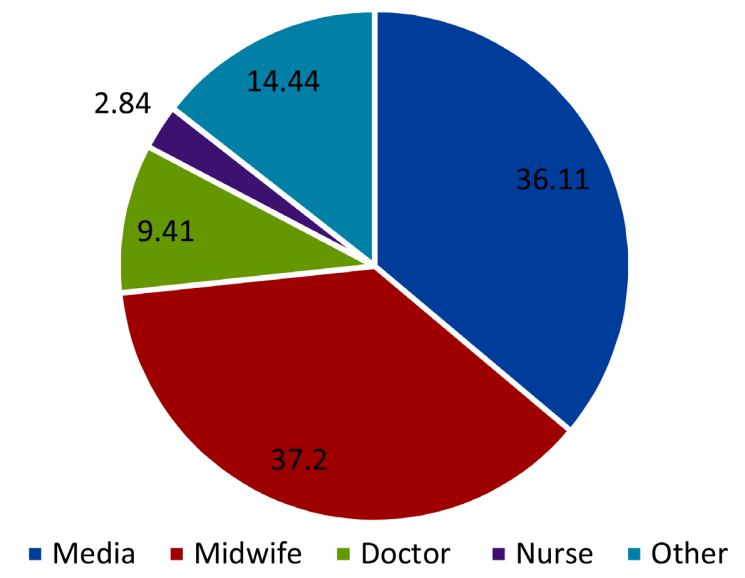

Figure 1. Women's source of information on breast cancer. 


\section{Discussion}

Our study was prospective and concerned women with no current breast pathology, who had never undergone mammography, who came for consultation and who had voluntarily agreed to participate in this study. This study has some limitations related to the selection bias of the population studied, the independent nature of each investigator which could influence the results and the number of women who participated in the survey. However, our study remains representative.

Our study focused on women over 30 years of age. Kiguli et al. [8] had considered the same age limit. Similar studies by Opoku et al. [9] and Donnelly et al. [10] focused on women aged above 35 and 40 years respectively. The choice of the age threshold is motivated by the age from which breast cancer would be more frequent and the age from which mammography would be more indicated. The mean age of our sample was 42.96 years. This age can be matched with those obtained by Donelly et al. [10] (44.9 years), and by Obajimi et al. [11] (40.2 years).

Our sample as well as that of Morse et al. [12] (44.1\%) was dominated by female traders. On the other hand, in the studies by Kiguli et al. [8] and Donnelly et al. [10], civil servants predominated with $43 \%$ and $34.1 \%$ respectively. The majority of women in our study $(75.9 \%)$ were educated. The same is true in the studies by Kiguli et al. [8] (77\%) and Obajimi et al. [11] (80\%). Women with a university education were poorly represented in our study (12.4\%), unlike the series by Donelly et al. [10] (33.3\%) and Obajimi et al. [11] (31.8\%).

Awareness of breast cancer is essential to allow its early diagnosis. In our study, $88.8 \%$ of women had some knowledge about breast cancer. This figure, although high, is lower than those found by Yusof et al. [13] (99.1\%) and by Morse et al. [12] (98.2\%). Awareness of breast cancer was not directly correlated with awareness of mammography. Although the latter is not a new screening method, the level of awareness and its use in screening in most developing countries is quite poor [14]. In Togo, women who had some knowledge about mammography accounted for only $20.8 \%$. This rate, as low as it is, is higher than that of Obajimi et al. [11] (5\%). On the other hand, Kiguli et al. [8], as well as Akinola et al. [15] found higher rates, respectively $29 \%$ and $40.5 \%$. This proves that in general, more than half of women had no information about mammography. The lack of information among women about mammography in African countries can be explained by insufficient mammography services. In several countries in sub-Saharan Africa, mammography can only be performed in hospitals in the capital, leaving the majority of women and even health workers in rural areas less informed about mammography.

Older women are less informed about mammography, as revealed in our study and that of Obajimi et al. [11], although mammographic screening for breast cancer is most indicated for them. Indeed, the women most likely to benefit from mammography are those whose age is between 50 and 69 years, because of the low breast density and the high frequency of breast cancer in this 
age group [9].

The low level of education of majority of women is another reason for the lack of information, since women do not know how to access precise information on breast cancer, especially since knowledge of mammography would be related to women's level of education. Thus, better educated women would be better informed than less educated women regardless of age [8]. In our study, out of the women who had heard of mammography, $37.74 \%$ had a university education. The same results were reported by Obajimi et al. [11] and Akinola et al. [15].

There is also a relation between the level of information and the profession. Akinola et al. [15] reported an awareness level of 40.5\% among healthcare workers. In our study, $63 \%$ of civil servants had knowledge of mammography.

Overall, the level of information about breast cancer diagnostics, especially mammography, is clearly very low. In our study, $83.3 \%$ of women found the information about mammography screening for breast cancer unsatisfactory. There are few sources of information, education and communication about the various diseases in general and breast cancer in particular. The main source of information in our study was midwives (37.2\%) followed by mass media (36.2\%). Indeed, prenatal consultations would represent a real opportunity to inform women about breast cancer and the means of screening. This explains the fact that midwives were the main source of information in our study. Physicians represented only $9.4 \%$ of information sources in our study, compared to $24.4 \%$ in the study by Donnelly et al. [10]. This is in contrast with the result of a study in the Western world, which found that $92 \%$ of women were informed by doctors [16]. In Africa, the lack of information from medical personnel is said to be partly filled by the mass media. Thus, the mass media are also an important source of information as demonstrated in our study, as well as those of Obajimi et al. [11], and Opoku et al. [9]. This is explained by the fact that in most African countries the media, especially local radio stations, are very accessible.

\section{Conclusion}

In conclusion, breast cancer remains a public health concern. It requires early detection for effective management. This study shows that there is a lack of information for women about mammographic screening, which is almost absent in sub-Saharan countries. The level of information of women on mammographic screening for breast cancer would be related to age, occupation and level of education. The implementation of strategies, involving all stakeholders to increase the level of information on mammographic screening for breast cancer, would reduce the death rates related to this cancer.

\section{Acknowledgements}

The authors thank the authorities and the health professionals of campus tcheatching Hospital and surrounding health facilities for their help in data collection and all the participants. 


\section{Conflicts of Interest}

The authors declare no conflicts of interest regarding the publication of this paper.

\section{References}

[1] Institut National du Cancer (INCa) (2008) Cancer du sein: Indications de la radiothérapie. https://www.e-cancer.fr/soins/recommandations/cancers-du-sein

[2] Ferlay, J., Soerjomataram, I., Dikshit, R., Eser, S., Mathers, C., Rebelo, M., et al. (2015) Cancer Incidence and Mortality Worldwide: Sources, Methods and Major Patterns in GLOBOCAN 2012. International Journal of Cancer, 136, E359-E386. https://doi.org/10.1002/ijc.29210

[3] Ly, M., Antoine, M., André, F., Callard, P., Bernaudin, J.F. and Diallo, D.A. (2011) Le cancer du sein chez la femme de l'Afrique sub-saharienne: Etat actuel des connaissances. Bulletin du Cancer, 98, 797-806. https://doi.org/10.1684/bdc.2011.1392

[4] Amégbor, K., Darre, T., Ayéna, K.D., Padaro, E., Tengué, K., Abalo, A., et al. (2011) Cancers in Togo from 1984 to 2008. Epidemiological and Pathological Aspects of 5251 Cases. Journal of Cancer Epidemiology, 2011, Article ID: 319872. https://doi.org/10.1155/2011/319872

[5] Darré, T., Walla, A., Kpatcha, T.M., Aboubakari, A.S., Maneh, N., Koulinga, M., et al. (2016) Cancers in the Elderly Seen in Anatomical Pathology Laboratory in Lomé, Togo. Open Journal of Pathology, 6, 26-31. https://doi.org/10.4236/ojpathology.2016.61005

[6] Harouna, Y.D. (2001) La femme d'Afrique et son chirurgien face au cancer du sein. Médecine d’ Afrique Noire, 48, 82-83.

[7] Agoda-Koussemal, K., Adjenou, K.V., Folligan, K., Adama-Hondegla, A.B., Amegnito, K., Awobanou, K. and N'dakena, K.G. (2010) Apport de la mammographie au diagnostic de la pathologie mammaire au Chu tokoin de Lome. Journal de la Recherche Scientifique de I Université de Lomé, 12, 1-3. https://doi.org/10.4314/jrsul.v12i2.68031

[8] Kiguli-Malwadde, E., Mubuuke, A.G., Businge, F., Kawooya, G.M., Nakatudde, R., Byanyima, K.R., et al. (2010) Current Knowledge, Attitudes and Practices of Women on Breast Cancer and Mammography at Mulago Hospital. Pan African Medical Journal, 5, Article No. 9.

[9] Opoku, S.Y., Benwell, M. and Yarney, J. (2012) Knowledge, Attitudes, Beliefs, Behaviour and Breast Cancer Screening Practices in Ghana, West Africa. Pan African Medical Journal, 11, Article No. 28.

[10] Donnelly, T.T., Al Khater, A.H., Al-Bader, S.B., Al Kuwari, M.G., Al-Meer, N., Malik, M., et al. (2013) Beliefs and Attitudes about Breast Cancer and Screening Practices among Arab Women Living in Qatar: A Cross-Sectional Study. BMC Women's Health, 13, Article No. 49. https://doi.org/10.1186/1472-6874-13-49

[11] Obajimi, M.O., Ajayi, I.O., Oluwasola, A.O., Adedokun, B.O., Adeniji-Sofoluwe, A.T., Mosuro, O.A., et al. (2013) Level of Awareness of Mammography among Women Attending out Patient Clinics in a Teaching Hospital in Ibadan, South-West Nigeria. BMC Public Health, 13, Article No. 40. https://doi.org/10.1186/1471-2458-13-40

[12] Morse, E.P., Maegga, B., Joseph, G. and Miesfeldt, S. (2014) Breast Cancer Knowledge, Beliefs, and Screening Practices among Women Seeking Care at District Hospitals in Dar es Salaam, Tanzania. Breast Cancer, 8, 73-79.

https://doi.org/10.4137/BCBCR.S13745 
[13] Yusof, A., Chia, Y.C. and Hasni, Y.M. (2014) Awareness and Prevalence of Mammography Screening and Its Predictors-A Cross Sectional Study in a Primary Care Clinic in Malaysia. Asian Pacific Journal of Cancer Prevention, 15, 8095-8099. https://doi.org/10.7314/APJCP.2014.15.19.8095

[14] Anim, J.T. (1993) Breast Cancer in Sub-Saharan African Women. African Journal of Medicine and Medical Sciences, 22, 5-10.

[15] Akinola, R., Wright, K., Osunfidiya, O., Orogbemi, O. and Akinola, O. (2011) Mammography and Mammographic Screening: Are Female Patients at a Teaching Hospital in Lagos, Nigeria, Aware of These Procedures? Diagnostic and Interventional Radiology, 17, 125-129. https://doi.org/10.4261/1305-3825.DIR.3078-09.2

[16] Yucel, A., Degirmenci, B., Acar, M., Ellidokuz, H., Albayrak, R. and Haktanir, A (2005) Knowledge about Breast Cancer and Mammography in Breast Cancer Screening among Women Awaiting Mammography. Turkish Journal of Medical Sciences, 35, 35-42. 